\title{
Effects of Instructor Gender and Visual and Auditory Melodic Recorded Instruction on Sequential Working Memory Recall in Individuals with and without Autism Spectrum Disorder
}

\author{
Edward Todd Schwartzberg ${ }^{1 *}$, Michael J Silverman $^{1}$ \\ 1 University of Minnesota - School of Music \\ *schwa155@umn.edu
}

Received: 19 October 2018 Accepted: 26 March 2019 Published: 1 July 2019

Editor: Daphne Joan Rickson Reviewers: Jason Noone, Melissa Murphy

\begin{abstract}
There is a lack of empirical inquiry concerning the effect of the therapist's binary gender and aspects of visual and auditory melodic instruction on working memory recall in individuals with autism spectrum disorder (ASD). The purpose of this study was to examine the effects of instructor gender and visual and auditory melodic instruction on working memory in individuals with ASD. Participants ( $n=38$ individuals with ASD and $n=18$ neurotypical [NT] university students) viewed or listened to four melodic sequences of seven randomized monosyllabic words sung by female and male instructors. To assess working memory, participants' tasks were to sequentially recall the paired information presented within each condition. There was no significant within-group difference between either the male and female instructor conditions or the visual + auditory or auditory only melodic instruction. Although not significant, participants tended to have slightly higher mean recall for the male instructor with visual + auditory stimuli condition and lower mean recall for the female instructor with auditory only stimuli condition. There was a significant between-group difference with the NT group having greater recall accuracy than the ASD group. Regardless of group or condition, participants tended to have greater recall accuracy at primary and recency serial positions. As individuals with ASD may have unique learning challenges, information paired with music may be delivered in multi-sensory ways to increase the likelihood of recall and subsequent learning. Implications for clinical practice, limitations of the study, and suggestions for future research are provided.
\end{abstract}

Keywords: autism, video modeling, instructor gender, working memory, rhythm, melody 


\section{Introduction}

Researchers continue to identify evidence-based interventions (NAC, 2009,, 2015) that can offer safe, success-oriented, cost-effective, and generalizable results for individuals with autism spectrum disorder (ASD). Providing a multi-sensory experience that stimulates a myriad areas in the brain may improve working memory and subsequent learning for individuals with ASD (Berger, 2002). While visual supports and video modeling (NAC, 2009, 2015) are best-practice approaches used to communicate with and teach individuals with ASD, there is a lack of empirical inquiry concerning the presentation of the information to be learned. As many music therapists work with individuals with ASD and approximately $87 \%$ of music therapy clinicians are female (AMTA, 2018), investigating if the gender of the care provider impacts client learning is warranted. In addition to the care provider's gender, visual and auditory aspects of the presentation of information may also impact recall. Therefore, the purpose of this study was to examine the effects of instructor gender and visual and auditory melodic instruction on working memory in individuals with ASD.

\section{Literature Review}

Researchers from the National Center for Education Statistics have investigated teacher gender discrepancies. During the 2015 - 2016 school year, they concluded that approximately $77 \%$ of public school teachers were female (National Center for Education Statistics, 2017). Due to the gender difference in the teacher workforce, researchers have investigated same versus different gender pupil-teacher interactions. In elementary public schools, Ehrenberg, Goldhaber, and Brewer (1995) concluded that female students' test scores in mathematics and science did not increase more rapidly when the teacher was a female than when the teacher was a male. Mancus (1992) concluded that while elementary aged girls and boys attributed authority to male teachers, elementary aged girls and boys attributed academic competence of the teacher most often to female teachers. Boys tended to follow an egalitarian pattern of positive attributions, with slightly more made to female teachers. Dee (2005) asserted that both male and female students were more likely to be perceived as disruptive by an opposite gender teacher. In a longitudinal study involving 54,000 students, Bettinger and Long (2005) concluded that female instructors might positively influence female freshman college students' course selections and major choices, thus supporting a possible role-model effect. The researchers also noted that male faculty may positively impact same-gender student interest in a subject of study.

\section{Impact of Gender on Instruction and Therapy}

Medically-oriented researchers have investigated the influences of care provider gender and care receiver gender and have concluded that preexisting stereotypes, expectations, or actual differences in physicians' behaviors, and the tone and content of the medical visit might be different depending on physician gender. Hall and Roter (2002) conducted a meta-analysis and concluded that patients, regardless of gender, spoke more to female physicians than to male physicians and disclosed more biomedical and psychosocial information. Similarly, Bhati (2014) asserted a general "female effect" and concluded that the female and male clients matched with female therapists reported a higher therapeutic alliance, collaborative role enactment, and empathetic resonance than when the female and male clients were matched with male therapists. In a related investigation, Pikus and Heavey (1996) concluded that the majority of female clients preferred working with female therapists. Female clients specifically commented that they felt more comfortable talking with someone of the same gender while most male clients expressed no preference for therapist gender. In addition to gender matching potentially influencing therapeutic alliance, gender matching also appears to be a factor in determining treatment retention. Wintersteen, Mensinger, and Diamond (2005) and Shiner, Westgate, Harik, Watts, and Schnurr (2017) reported that female 
patients who were treated by female therapists had the highest retention rate while male patients who were treated by male therapists had the lowest retention rate.

\section{Neural Connectivity and Working Memory in Autism Spectrum Disorder}

Individuals with ASD often present with deficits in cognitive processing (Bauman \& Kemper, 2005; DiCicco-Bloom et al., 2006). These deficits are specifically apparent in the frontal lobe, the area of the brain primarily responsible for executive functioning (Geurts, Verte, Oosterlaan, Roeyers, \& Sergeant, 2004; Verte, Geurts, Roeyers, Oosterlaan, \& Sergeant, 2006). Researchers have also concluded that hyper-connectivity appears to exist between the prefrontal and parietal cortices and a hypoconnectivity exists between the sensory-motor regions (Holiga et al., 2019). Researchers have labeled this difference in neural connectivity as the "underconnectivity theory" (Just, Cherkassky, Keller \& Minshew, 2004; Just \& Varma, 2007). Proponents of this theory have asserted that inter-regional connective in the frontal lobe of the brain is disrupted in autism due to poor frontal-posterior connectivity (Just, Keller, Malave, Kana, \& Varma, 2012). Holiga and colleagues (2019) concluded that understanding brain connectivity alterations in ASD might help the development of better diagnostic and therapeutic tools.

Working memory is the ability to simultaneously store and process information (Baltruschat et al., 2011). Pennington and Ozonoff (1996) concluded that working memory functions as an organizational aspect of memory and has a role in goal-directed behavior. Responsible for aspects of executive functioning, working memory is integral to linguistic processing (Elliot, 2003) and is primarily processed in the dorsal and lateral pre-frontal cortex (Nolte, 2002, p. 549). As a result of the structural differences in the neural connectivity of the brain of individuals with ASD, individuals with ASD regularly demonstrate deficits in working memory that can lead to challenges in understanding social cues, academic progress, and independent living skills.

\section{Non-Music Based Approaches to Enhance Working Memory}

In order to improve cognitive processing for individuals with ASD, experts have identified modeling and visual supports as two of the 11 established evidence-based practices (NAC, 2009,, 2015). Video modeling is a combination of both modeling (Bandura, 1977) and visual supports (Quill, 1997) and can be an effective approach for teaching social skills, self-care skills, and motor skills (Bellini \& Akullian, 2007; Charlop-Christy \& Daneshvar, 2003; Charlop-Christy, Le, \& Freedman, 2000; Sherer et al., 2001). Video modeling may also be considered a form of dual coding (Paivo, 1991), wherein the target information is delivered and received through both the auditory and visual channels. To assist with video modeling, clinicians and teachers commonly used electronic recording devices such as the iPad® as an accessible and visually stimulating reinforcement of teaching. Since the advent of the iPad® in 2010, researchers have demonstrated the efficacy of the technology for academic, social, communication, and emotional regulation skill growth. Allen, Hartley, and Cain (2016) concluded that the iPad may be a tool to assist children's ability to generalize academic skills outside of the formal school environment.

Due to the importance of utilizing visual and auditory supports as effective enhancements to the educational and clinical environments of neurodiverse individuals, the use of the $\mathrm{iPad} \AA$ as an instructional tool has become more prevalent over the last decade. Therefore, researchers have investigated the effectiveness of this technology on academic and social skill achievement. Allen, Hartley, and Cain (2016) recommended that iPads® might motivate children to engage with learning. Maich and Hall (2015) offered suggestions for using iPads ${ }^{\circledR}$ for educational purposes, choosing appropriate applications, and integrating the technology into the inclusive classroom environments. Researchers have also investigated the use of iPad ${ }^{\circledR}$-based video modeling 
to teach numeracy skills (Jowett, Moore, \& Anderson, 2012), iPad®instruction on challenging behaviors and academic engagement for children with ASD (Neely, Rispoli, Camargo, Davis, \& Boles, 2013), and the use of video self-modeling on an iPad®to teach functional math skills to adolescents with ASD (Burton, Anderson, Prater, \& Dyches, 2013). El Zein et al. (2016) concluded that teacher directed instruction was more effective for increasing the accuracy of responding to curriculum-based measure probes than $\mathrm{iPad} \AA$ instruction. The researchers also recommended using the $\mathrm{iPad} \AA$ to teach students skills that would aid in enhancing their reading comprehension. Moreover, they identified that $\mathrm{iPad} \AA$ applications should incorporate modeling, prompting, visual supports, and positive reinforcement. As motivational processes directly impact knowledge acquisition and transfer, it would seem that the integration and usage of the $\mathrm{iPad}{ }^{\circledR}$ in educational and therapeutic environments should be further explored (Wang, Teng, \& Chen, 2015).

\section{Paired Associate Music to Enhance Working Memory}

Care providers often utilize music for social and academic skill attainment (Brownell, 2002; Schwartzberg \& Silverman, 2013). Researchers have used melody to assist with the immediate recall of information for individuals with neurologic disabilities (Schwartzberg \& Silverman, 2012; Thaut, Peterson, McIntosh, \& Hoemberg, 2014). McElhinney and Annett (1996) concluded that there was a better overall recall of familiar words correctly recalled in a song condition than in a reading condition. Silverman and Schwartzberg (2014a) studied the effects of voice timbre (male versus female instructor) on the sequential working memory recall of university students and found better recall accuracy during the male voice conditions. Researchers have also concluded that music conditions were more effective than speech conditions on short- and long-term memory recall (Schwartzberg \& Silverman, 2012). In a related study, researchers investigated the effects of presentation style and musical elements on the working memory of individuals with and without ASD (Schwartzberg \& Silverman, 2018). Participants demonstrated significantly more accurate recall during the live conditions than the recorded conditions.

Although music and iPads are frequently used in an attempt to augment learning, no researcher has investigated the effects of instructor gender and video recorded musicbased instruction on the sequential working memory of individuals with ASD. These data would be important to determine if instructor gender and aspects of video instruction paired with music will have differing effects on the sequential working memory of individuals with and without ASD. Therefore, the purpose of this study was to examine the effects of instructor gender and visual and auditory melodic video recorded instruction on working memory in individuals with ASD. Specific research questions included:

1. Will a female or male instructor yield more accurate sequential working memory in individuals with ASD?

2. Will visual + auditory or auditory only melodic instruction yield more accurate sequential working memory in individuals with ASD?

3. Will there be a significant difference in sequential working memory between individuals with ASD and neuro-typical (NT) university students?

4. In what serial positions is recall most accurate?

\section{Method}

\section{Research Participants}

\section{Phase One}

The researchers' affiliated Institutional Review Board (IRB) approved this study before data collection initiated (1505S70921). Participants in phase one were individuals 
with a primary diagnosis of ASD $(n=38)$. The principal investigator (PI), a boardcertified music therapist with 20 years of clinical experience, initially recruited 108 individuals to participate in the study. All 108 consented and assented to participate in the study. Of the 108 consenting individuals with ASD, 38 participated in all four conditions of the study. Therefore, only these 38 participants were included in the data analysis. Data were collected during the participant's relaxation (rest) hour and therefore some that consented may have been sleeping or refused due to relaxation. Of the 38 participants, 32 were male and six were female. The gender imbalance is similar to the commonly asserted three to one imbalance of the male-to-female prevalence ratio in ASD (Loomes, Hull, \& Mandy, 2017). The ages of the participants ranged from ten to 32 years with a mean age of 17.00 years $(S D=5.76)$.

Participants were recruited from a convenience sample at a summer camp for individuals with ASD where the philosophy and mission of the camp is to provide a week of vacation for individuals with ASD. Moreover, because the organization that operates the camp does not request or collect personal health information, the PI did not obtain personal health information such as present level of academic progress, severity of ASD, or level of cognitive functioning. Therefore, no clinical/educational assessment was conducted, no treatment plan was developed, and no datum was taken on the progress of the campers.

\section{Phase Two}

Participants $(n=18)$ in phase two were neuro-typical (NT) university students registered for an undergraduate Introduction to Music Therapy course offered at an Upper Midwest University in the United States. Of the 18 participants, three were male and 15 were female. The ages of the participants ranged from 18 to 24 years with a mean age of 18.72 years $(S D=1.53)$.

\section{Recruitment}

\section{Phase One}

At the onset of the study, the PI had been the music therapist at the camp for 15 years and had therefore developed a positive rapport with the campers. The PI initially met with potential participants and their legal guardian(s) during check-in on the first day of camp. During this time, the PI answered their questions and concerns, and explained and obtained informed consent from the legal guardian(s) and assent from the potential participants. The assent form was created with visual supports to assist with the reading and comprehension of the information presented on the assent form. If potential participants did not understand the assent form, their legal guardian(s) helped read and confirm their understanding of the information presented on the assent form. All participants could withdraw from the study at any time without penalty and received no payment or compensation to participate in the study.

\section{Phase Two}

On the first day of the semester, the PI verbally recruited undergraduate students who were registered for an Introduction to Music Therapy course. Potential participants were then given one week to consider their commitment to participation. The PI returned to the class the following week to obtain written consent from those interested in participating in the research study. There was no course incentive or negative repercussion to participate and participation was thus voluntary. Consistent with previous course enrollments indicating composition of the class tends to be mostly female, the majority of participants in phase two were female. 


\section{Digit Test}

Adapted from Schwartzberg and Silverman (2012), the researchers utilized a visual recall test that included four different seven-picture sequences using monosyllabic words: Car, house, boat, book, tree, horse and dog. Each laminated picture measured one-inch by half-inch and were created using the Boardmaker (Mayer-Johnson, 2008) computer program. The PI provided the participants with the score sheet and laminated versions of the pictures. Participants placed their laminated pictures on a scoring sheet that depicted a horizontal table with seven two-inch by one-inch squares. The researchers created four randomized conditions: (a) female instructor with visual + auditory stimuli, (b) female instructor with auditory only, (c) male instructor with visual + auditory stimuli, (d) male instructor with auditory only. In an attempt to control for learning and order effects, the delivery order of the conditions was randomized using a Latin Square Design. All conditions were previously video recorded onto an iPad in an attempt to control the independent variables. Both the female and male instructors were selected because they would be unknown to the participants. The video recording for the visual + auditory stimuli conditions depicted the instructor standing behind a table with the score sheet described above on the table. The participants then saw the instructor's face and saw the instructor place the laminated pictures, one at a time, on the score sheet as the melody was sung. The auditory only conditions were pre-recorded and depicted a blank screen with only the audio of each instructor presenting the melody.

Adapted from Schwartzberg and Silverman (2018), the rhythmic and melodic contours were developed to meet two criteria: a) Information should be rhythmically chunked in clusters; and b) the melody should be a narrow range with the same beginning and ending note. Three clusters formed the rhythmic pattern for all conditions: eighth note-eighth note-quarter note, eighth note-eighth note-quarter note, and quarter note. Each melodic pattern began and ended on C4 and did not extend beyond A4. Each melodic condition began with an ascending pattern and then descended at the half way position. The four conditions are visual depicted in Appendix A.

Each task required the participants to visually identify their seven monosyllabic pictures and then place them in the order they saw and heard the PI present them. The order of the seven pictures was randomized and set by condition (each condition had one randomized order for the seven familiar pictures). Each correct position received one point with a high score of seven and a low score of zero for each condition.

\section{Procedure}

All participants watched each video on a $4^{\text {th }}$ Generation Apple iPad® ${ }^{\circledR}$ with Retina Display, Model MD511LL/A. To assess working memory, participants' tasks were to sequentially recall the paired information presented within each condition. At the conclusion of each condition, the PI verbally and visually prompted the participants to place the seven pictures in the order in which they saw and heard them presented.

\section{Phase One}

Data collection took place during the camper's daily scheduled relaxation time (a scheduled 60-min block of time, when no other camp activities are scheduled). Data collection took place in the dining hall of camp when no other campers or staff members were present. The PI escorted each participant to the dining hall. The PI then read the assent form to the participants, obtained their permission to participate, and delivered the four randomized conditions.

\section{Phase Two}

A research assistant collected the data utilizing the same procedures described in phase one. Data collection took place during the participant's weekly scheduled class and the research assistant escorted the participants to a private lab room. In an attempt to en- 
sure reliability of the procedures and test, the PI taught the research assistant the same protocol used for data collection during phase one. The research assistant then read the consent form to the participants, obtained their permission to participant, and delivered the four randomized conditions.

\section{Power analysis}

The researchers conducted a power analysis using G*Power (Faul, Erdfelder, Buchner, \& Lang, 2009) to determine adequate sample size. Power analyses indicated 54 total participants were necessary in order to detect a medium partial $\mathrm{n}^{2}(.25)$ when $?=0.05$ for a power of 0.95 with two independent treatment groups using a repeated measures analysis of variance consisting of within and between interactions.

\section{Quantitative Analyses}

In the original four-way repeated measures analysis of variance (ANOVA), there was no significant main effect or significant interaction between order and the other variables (all $p>$.05). We therefore removed order from all subsequent analyses. We then utilized a three-way repeated measures ANOVA where within-subject variables were instructor gender (female versus male) and presentation style (auditory only versus visual + auditory stimuli) and one between-subjects variable (ASD group versus NT group). We checked to ensure that assumptions needed for the statistical tests were met by using Box's Test of Equality of Covariance Matrices. This result was not significant, $p=.121$. Analyses were computed utilizing SPSS version 19.0.

\section{Results}

The overall model of the three-way repeated measures ANOVA was not significant, $F(1,54)=0.008, p=.928$, partial $n^{2}=.000$.

Research question one: There was no significant difference in sequential recall between male and female instructors, $F(1,54)=1.432, p=.237$, partial $n^{2}=.026$. Although not significant, the mean recall for the male instructor $(M=3.59, S E=0.17)$ tended to be slightly higher than for the female instructor $(M=3.35, S E=0.18)$.

Research question two: There was no significant recall difference between visual + auditory stimuli condition and the auditory only condition, $F(1,54)=1.824, p=$ .182 , partial $n^{2}=.033$. Although not significant, the mean recall tended to be slightly higher for the visual + auditory stimuli condition $(M=3.62, S E=0.20)$ than for the auditory only condition $(M=3.32, S E=0.16)$. A summary of the descriptive statistics and pairwise comparisons is reported in Tables 1 and 2, respectively.

Research question three: There was a significant between-group difference concerning group, $F(1,54)=66.576, p<.001$, partial $n^{2}=.552$. The NT group demonstrated higher recall accuracy than the ASD group (mean difference $=2.36, p<.001,95 \% \mathrm{CI}$ $=1.78,2.94$ ).

Research question four: More accurate working memory recall is typically observed in sequential positions of primacy and recency and numerous interactions between serial position and other variables have been previously reported (Schwartzberg \& Silverman, 2012,, 2018; Ward, 2002). Therefore, the researchers did not statistically analyze recall data by serial position. Rather, the researchers graphed these data in Figures 1 and 2. Mean recall scores tended to be more accurate in serial positions of primacy and recency.

\section{Discussion}

According to the American Music Therapy Association, approximately 87\% of music therapy clinicians are female (AMTA, 2018). Moreover, many care providers pair music with information to be learned in an attempt to augment working memory. Therefore, the purpose of this study was to examine the effects of instructor gender and visual and auditory melodic instruction on working memory in individuals with ASD. 
Table 1

Descriptive statistics

\begin{tabular}{|c|c|c|c|c|c|c|c|c|}
\hline & \multicolumn{2}{|c|}{$\begin{array}{c}\text { Female Instructor } \\
\text { Visual + Auditory }\end{array}$} & \multicolumn{2}{c|}{$\begin{array}{c}\text { Female Instructor } \\
\text { Auditory Only }\end{array}$} & \multicolumn{2}{c|}{$\begin{array}{c}\text { Male Instructor } \\
\text { Visual + Auditory }\end{array}$} & \multicolumn{2}{c|}{$\begin{array}{c}\text { Male Instructor } \\
\text { Auditory Only }\end{array}$} \\
\hline ASD & $M$ & $S D$ & $M$ & $S D$ & $M$ & $S D$ & $M$ & $S D$ \\
\hline$(n=38)$ & 2.21 & 1.44 & 2.10 & 1.36 & 2.61 & 1.42 & 2.30 & 1.54 \\
\hline NT & 4.70 & 1.85 & 4.44 & 1.69 & 5.00 & 2.20 & 4.50 & 1.76 \\
$(n=18)$ & 3.00 & 1.94 & 2.84 & 1.84 & 3.38 & 2.03 & 2.98 & 1.91 \\
\hline $\begin{array}{c}\text { Total } \\
\text { Partici- } \\
\text { pants } \\
(N=56)\end{array}$ & & & & & & & & \\
\hline
\end{tabular}

Table 2

Pairwise comparisons $(\mathrm{N}=56)$

\begin{tabular}{|c|c|c|c|}
\hline Variables & Mean Difference & $p$ value & 95\% Confidence Interval \\
\hline Female versus Male & -0.242 & .202 & $-0.65,0.16$ \\
\hline $\begin{array}{c}\text { Auditory + Visual Stim- } \\
\text { uli verses Auditory } \\
\text { Stimuli Only }\end{array}$ & 0.30 & .18 & $-0.15,0.74$ \\
\hline $\begin{array}{c}\text { ASD versus NT } \\
\text { (n) }\end{array}$ & -2.36 & .001 & $-2.94,-1.78$ \\
\hline
\end{tabular}

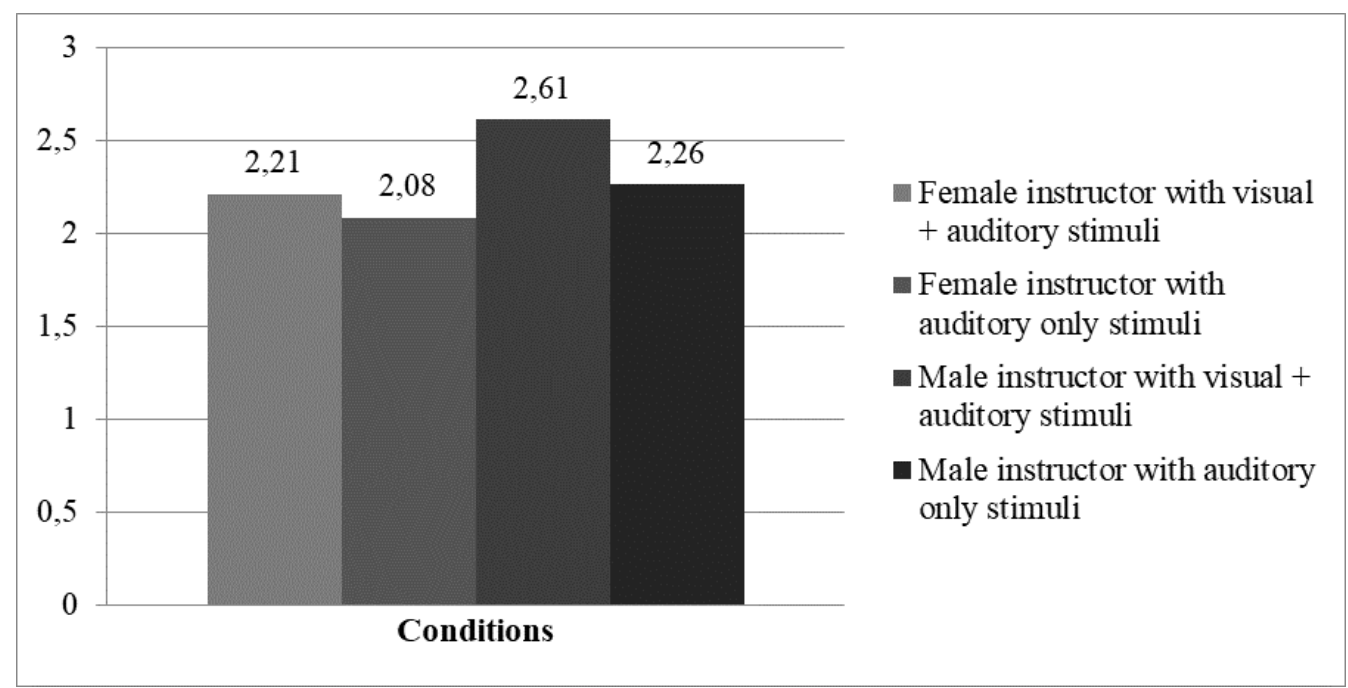

Figure 1

Mean \# of Correct Responses by Condition for Individuals with ASD

The mean recall of information presented by the male instructor tended to be slightly higher. Traditionally, male teachers have been perceived as more authoritative and 


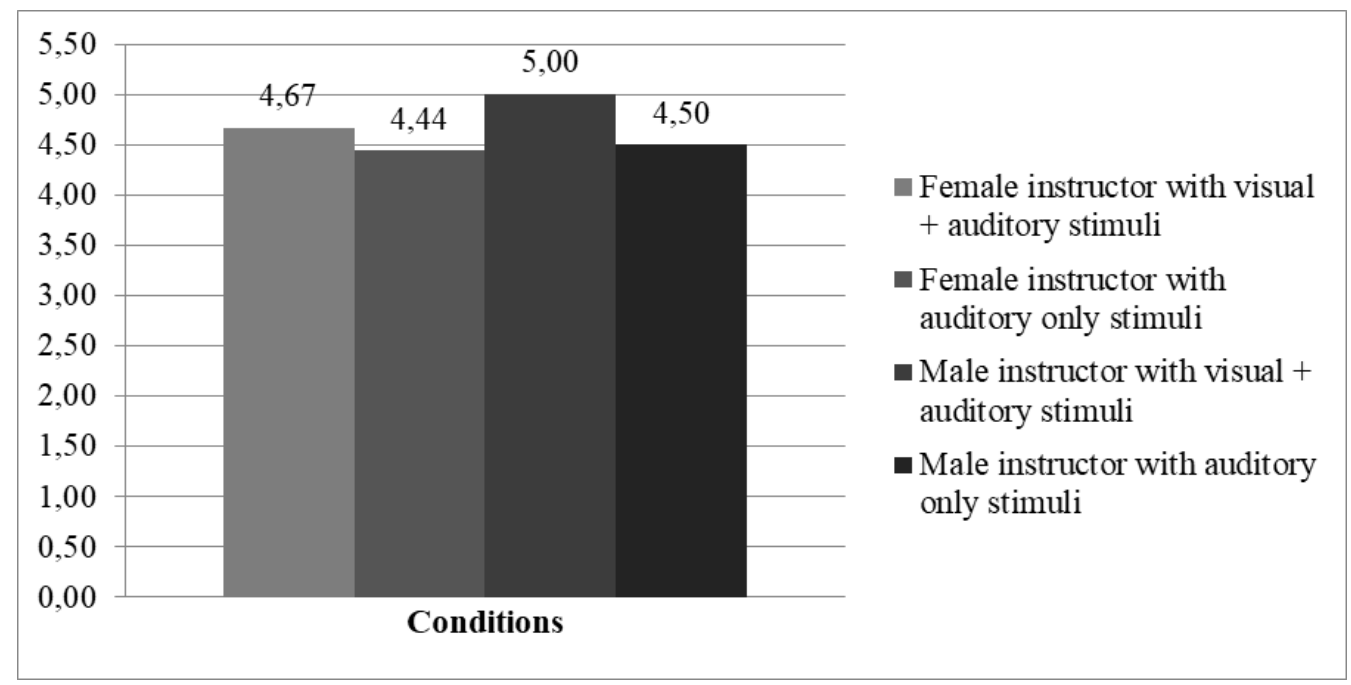

Figure 2

Mean \# of Correct Responses by Condition for Neuro-Typical University Students

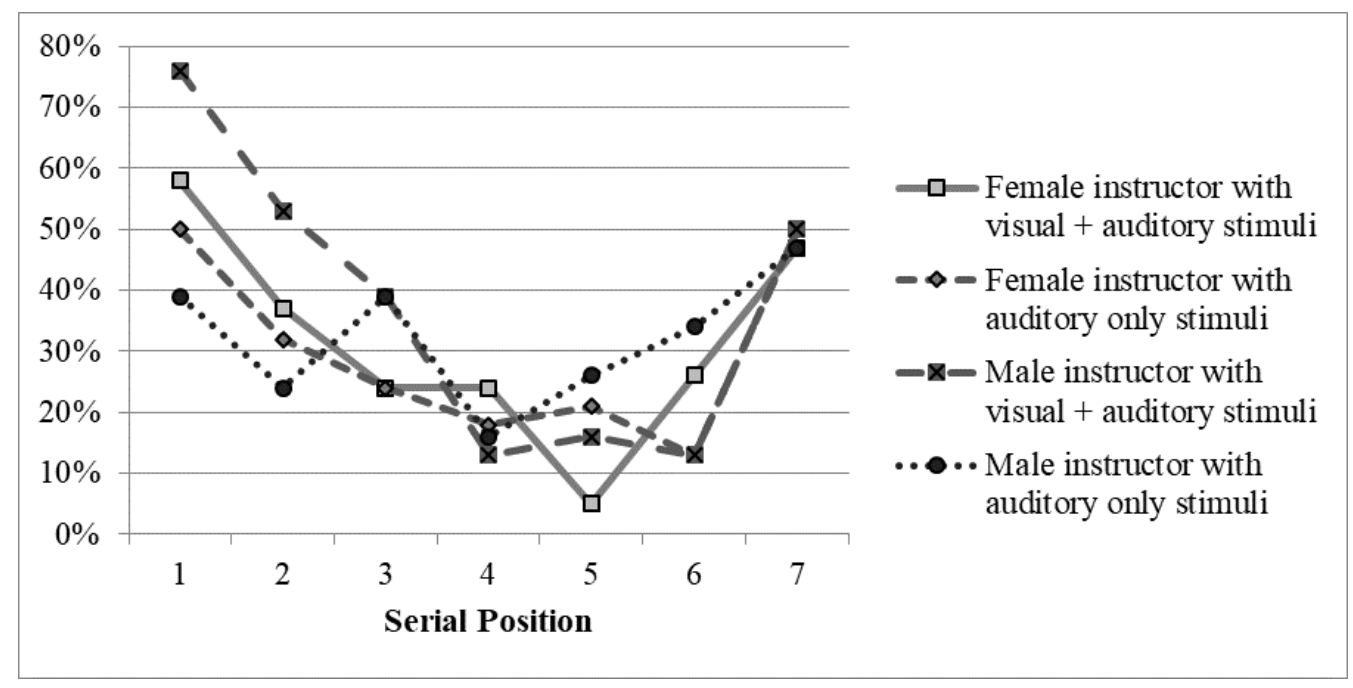

Figure 3

Percent correct mean responses by serial position for individuals with ASD

female teachers as more academically competent (Mancus, 1992). Moreover, these factors may be further challenged when an individual presents with deficits in perspective taking. Identifying how to demonstrate these perceived leadership traits, which can lead to enhanced rapport and therapeutic alliance, might be helpful for the achievement of targeted goals. However, as instructor gender results did not reach statistical significance and more males participated in the study, readers should be cautious regarding the conclusions.Care provider gender may not be an influential variable on the success of the client when music is integrated into the learning environment.

As demonstrated through the results of research question three and congruent with previous research (Schwartzberg \& Silverman, 2012,, 2018), there was a significant between-group difference with the NT group demonstrating higher levels of recall accuracy. The difference in age between the two groups may be one rationale for the significant difference in mean scores. While the mean ages of the two groups was only separated by one year, the participants in the ASD group ranged from ten to 32 and the participants in the NT group ranged from 18 to 24 years. Developmentally, the younger participants with ASD had less time to develop their working memory skills and compensatory strategies to assist with working memory recall than the NT college 


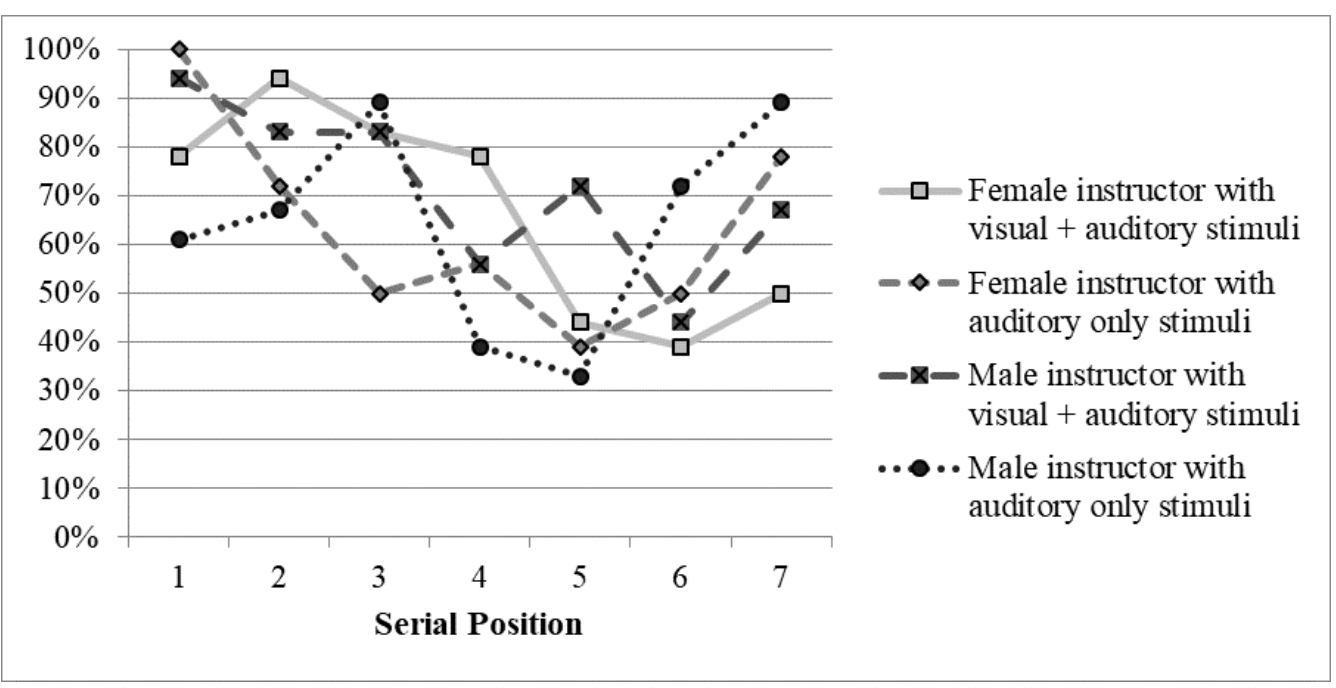

Figure 4

Percentage correct mean responses by serial position for neuro-typical university students

students. The neurological difference between the two groups is another potential rationale for this significant difference.

A limitation of the study was the access to participant health records as participants' cognitive functioning was not obtained through personal health information or formal assessment. Therefore, participants' memory recall was not analyzed according to cognitive functioning or other demographic factors. Another limitation was the use of a convenience sample for both groups as there was a disproportionate number of males in the ASD group and females in the NT group. Finally, the attrition that occurred in the ASD group represents an additional limitation.

Recall is a necessary cognitive function required for all aspects of cognitive, communication, motor, and social skills. Although within-group differences were not significant and generalizations are not warranted, results tended to be consistent with existing literature. As individuals with ASD may have unique learning challenges, information paired with music may be delivered in multi-sensory ways to increase the likelihood of recall and subsequent learning. Future research is warranted to continue to determine the preferred learning style and approaches that may yield the best immediate recall and enhance subsequent learning in individuals with ASD.

\section{Conflict of Interest Statement}

The authors do not have any actual or potential conflicts of interest including any financial, personal, or other relationships with other people or organizations within three years of beginning the submitted work that could inappropriately influence, or be perceived to influence, their work.

\section{About the authors}

Edward T. Schwartzberg (M.Ed., MT-BC) is a Senior Teaching Specialist and Clinic Coordinator in the Music Therapy Program.

Michael J. Silverman (Ph.D., MT-BC) is Professor and Program Director of Music Therapy.

\section{References}

Allen, M. L., Hartley, C., \& Cain, K. (2016). iPads and the use of "apps" by children with autism spectrum disorder: Do they promote learning? Frontiers in Psychology, 7, 1-7,

https://doi.org/10.3389/fpsyg.2016.01305. 
American Music Therapy Association. (2018). 2017 AMTA member survey and workforce analysis. Spring, MD: Author.

Baltruschat, L., Hasselhorn, M., Tarbox, J., Dixon, D. R., Najdowski, A. C., Mullins, R. D., \& Gould, E. R. (2011). Addressing working memory in children with autism through behavioral intervention. Research in Autism Spectrum Disorders, 5, 267-276, https://doi.org/ 10.1016/j.rasd.2010.04.008.

Bandura, A. (1977). Social learning theory. New York, NY: Prentice-Hall, Inc.

Bauman, M. L., \& Kemper, T. L. (2005). Neuroanatomic observations of the brain in autism: A review and future directions. International Journal of Developmental Neuroscience, 23, 183-187, https://doi.org/10.1016/j.ijdevneu.2004.09.006.

Bellini, S., \& Akullian, J. (2007). A meta-analysis of video modeling and video self-modeling interventions for children and adolescents with autism spectrum disorders. Exceptional Children, 73, 264-287, https://doi.org/10.1177/001440290707300301.

Berger, D. S. (2002). Music therapy, sensory integration and the autistic child. Philadelphia, PA: Jessica Kingsley Publishers.

Bettinger, E. P., \& Long, B. T. (2005). Do faculty serve as role models? The impact of instructor gender on female students. The American Economic Review, 95, 152-157, https://doi.org/10.1257/000282805774670149.

Bhati, K. S. (2014). Effect of client-therapist gender match on the therapeutic relationship: An exploratory analysis. Psychological Reports, 115, 565-583, https://doi.org/10.2466/ 21.02.PR0.115c23z1.

Brownell, M. D. (2002). Musically adapted social stories ${ }^{\mathrm{TM}}$ to modify behaviors in students with autism: Four case studies. Journal of Music Therapy, 39, 117-144, https://doi.org/10.1093/ jmt/39.2.117.

Burton, C., Anderson, D., Prater, M., \& Dyches, T. (2013). Video self-modeling on an iPad to teach functional math skills to adolescents with autism and intellectual disability. Focus on Autism and Other Developmental Disabilities, 28, 66-67, https://doi.org/https\%3A//doi.org/ 10.1177/1088357613478829.

Charlop-Christy, M., \& Daneshvar, S. (2003). Using video modeling to teach perspective taking to children with autism. Journal of Positive Behavior Interventions, 5, 12-21, https://doi.org/ 10.1177/10983007030050010101.

Charlop-Christy, M., \& Freedman, K. (2000). A comparison of video modeling within vivo modeling for teaching children with autism. Journal of Autism and Developmental Disorder, 30, 537-552, https://doi.org/10.1023/A\%3A1005635326276.

Dee, T. (2005). 'A teacher like me: Does race, ethnicity, or gender matter? The American Economic Review, 95, 158-165, https://doi.org/10.1257/000282805774670446.

DiCicco-Bloom, E., Lord, C., Zwaigenbaum, L., Courchesne, E., Dager, S. R., Schmitz, C., Schultz, R. T., Crawley, J., \& Young, L. J. (2006). The developmental neurobiology of autism spectrum disorder. Journal of Neuroscience, 26, 6897-6906, https://doi.org/10.1523/ JNEUROSCI.1712-06.2006.

Ehrenberg, R. G., Goldhaber, D. D., \& Brewer, D. J. (1995). Do teachers' race, gender, and ethnicity matter? Evidence from the national educational longitudinal study of 1988. Industrial and Labor Relations Review, 48, 547-561, https://doi.org/10.1177/ 001979399504800312.

El Zein, F., Gevarter, C., Bryant, B., Son, S., Bryant, D., Kim, M., \& Solis, M. (2016). A comparison between iPad-assisted and teacher-directed reading instruction for students with autism spectrum disorder (ASD). Journal of Developmental and Physical Disabilities, 28, 1-21, https://doi.org/10.1007/s10882-015-9458-9.

Elliot, R. (2003). Executive functions and their disorders: Imaging in clinical neuroscience. British Medical Journal, 65, 49-59.

Faul, F., Erdfelder, E., Buchner, A., \& Lang, AG. (2009). Statistical power analyses using $\mathrm{G}^{*}$ Power 3.1: Tests for correlation and regression analyses. Behavior Research Methods, 41, 1149-1160, https://doi.org/10.3758/BRM.41.4.1149. 
Geurts, H. M., Verté, S., Oosterlaan, J., Roeyers, H., \& Sergeant, J. (2004). How specific are executive functioning deficits in attention deficit hyperactivity disorder and autism? Journal of Child Psychology and Psychiatry, 45, 836-854, https://doi.org/10.1111/ j.1469-7610.2004.00276.x.

Hall, J. A., \& Roter, D. L. (2002). Do patients talk differently to male and female physicians? A meta-analytic review. Patient Education and Counseling, 48, 217-224, https://doi.org/ 10.1016/S0738-3991(02)00174-X.

Hardy, M. W., \& LaGasse, B. (2013). Rhythm, movement, and autism. Using rhythmic rehabilitation as a model for autism. Frontiers in Integrative Neuroscience, 28, https://doi.org/10.3389/fnint.2013.00019.

Holiga, S., Hipp, J. F., Chatham, C. H., Garces, P., Spooren, W., D’Ardhury, X. L., \& Dukart, J. (2019). Patients with autism spectrum disorders display reproducible functional connectivity alterations. Science Translational Medicine, 11, https://doi.org/10.1126/ scitranslmed.aat9223.

Jowett, E. L., Moore, D. W., \& Anderson, A. (2012). Using an iPad-based video modeling package to teach numeracy skills to a child with an autism spectrum disorder. Developmental Neurorehabilitation, 15, 304-312, https://doi.org/10.3109/ 17518423.2012.682168.

Just, M. A., Cherkassky, V. L., Keller, T. A., Kana, R. K., \& Minshew, N. J. (2007). Functional and anatomical cortical underconnectivity in autism: Evidence from an fMRI study of an executive function task and corpus callosum morphometry. Cerebral Cortex, 17, 951-961, https://doi.org/10.1093/cercor/bhl006.

Just, M. A., Cherkassky, V. L., Keller, T. A., \& Minshew, N. J. (2004). Cortical activation and synchronization during sentence comprehension in high-functioning autism: Evidence of underconnectivity. Brain, 127, 1811-1821, https://doi.org/10.1093/brain/awh199.

Just, M. A., Keller, T. A., Malave, V. L., Kana, R. K., \& Varma, S. (2012). Autism as a neural systems disorder: A theory of frontal-posterior underconnectivity. Neuroscience and Biobehavioral Reviews, 36, 1292-1313, https://doi.org/10.1016/j.neubiorev.2012.02.007.

Just, M. A., \& Varma, S. (2007). The organization of thinking: What functional brain imaging reveals about the neuroarchitecture of complex cognition. Cognitive, Affective, and Behavioral Neuroscience, 7, 153-191, https://doi.org/10.3758/CABN.7.3.153.

Kaplan, R. S., \& Steele, A. L. (2005). An analysis of music therapy program goals and outcomes for clients with diagnoses on the autism spectrum. Journal of Music Therapy, 25, 73-84, https://doi.org/10.1093/jmt/42.1.2.

Kassim, W. Z. W. (2018). Utilizing dual coding theory and animated images to enhance ESL students' vocabulary learning. The English Teacher, 57, 81-91.

Kern, P., Rivera, N. R., Chandler, A., \& Humpal, M. (2013). Music therapy services for individuals with autism spectrum disorder: A survey of clinical practices and training needs. Journal of Music Therapy, 50, 274-303, https://doi.org/10.1093/jmt/50.4.274.

LaGasse, B. (2014). Effects of a music therapy group intervention on enhancing social skills in children with autism. Journal of Music Therapy, 51, 250-275, https://doi.org/10.1093/jmt/ thu012.

Loomes, R., Hull, L., \& Mandy, WPL. (2017). What is the male-to-female ratio in autism spectrum disorder? A systematic review and meta-analysis. Journal of the American Academy of Child and Adolescent Psychiatry, 55, 466-474, https://doi.org/10.1016/ j.jaac.2017.03.013.

Maich, K., \& Hall, C. (2015). Implementing iPads in the inclusive classroom setting. Intervention in School and Clinic, 1, 1-6, https://doi.org/10.1177/1053451215585793.

Mancus, D. S. (1992). Influence of male teachers on elementary school children's stereotyping of teacher competence. Sex Roles, 26, 109-128, https://doi.org/https\%3A//doi.org/ 10.1007/BF00289753.

Mayer-Johnson, L. L. C. (2008). Boardmaker version 6.0 for Mac. Pittsburgh, PA: Dynavox Mayer-Johnson, Inc. 
McElhinney, M., \& Annett, J. M. (1996). Pattern of efficacy of a musical mnemonic on recall of familiar words over several presentations. Perceptual and Motor Skills, 82, 395-400, https://doi.org/10.2466/pms.1996.82.2.395.

Munson, S., Meltzoff, A., \& Abbott, R. (2008). Neurocognitive predictors of social and communicative developmental trajectories in preschoolers with autism spectrum disorders. Journal of the International Neuropsychological Society, 14, 956-966, https://doi.org/ $10.1017 /$ S1355617708081393.

National Autism Center. (2009). National standards project: Findings and conclusions. Randolph, MA.: .

National Autism Center. (2015). Findings and conclusions: National standards project, phase 2. Randolph, MA.: .

National Center for Education Statistics. (2013). National center for education statistics, schools and staffing survey (SASS), "Public School Teacher Data File," 1987-88 through 2011 - 2012. U.S. Department of Education. Washington, D.C.

National Center for Education Statistics. (2017). Digest of Education Statistics. Retrieved from https://nces.ed.gov/programs/digest/d17/ch_2.asp.

Neely, L., Rispoli, M., Camargo, S., Davis, H., \& Boles, M. (2013). The effect of instructional use of an iPad on challenging behavior and academic engagement for two students with autism. Research in Autism Spectrum Disorders, 7, 509-516, https://doi.org/10.1016/ j.rasd.2012.12.004.

Nolte, J. (2002). The human brain: An introduction to its functional anatomy (5th ed.). St. Louis, MO: Mosby, Inc.

Odom, S. L., Collet-Klingenberg, L., Rogers, S. J., \& Hatton, D. D. (2010). Evidence-based practices in interventions for children and youth with autism spectrum disorders. Preventing School Failure, 54, 275-282, https://doi.org/10.1080/10459881003785506.

Paivio, A. (1991). Dual coding theory: Retrospect and current status. Canadian Journal of Psychology, 45, 255-287, https://doi.org/10.1037/h0084295.

Pennington, B. F., \& Ozonoff, S. (1996). Executive functions and developmental psychopathology. Journal of Child Psychology and Psychiatry, 37(1), 51-87.

Pikus, C. F., \& Heavey, C. L. (1996). Client preferences for therapist gender. Journal of College Student Psychotherapy, 10, 35-43, https://doi.org/10.1300/J035v10n04_05.

Quill, K. A. (1997). Instructional considerations for young children with autism: The rationale for visually cued instruction. Journal of Autism and Developmental Disorder, 27, 697-714, https://doi.org/10.1023/A\%3A1025806900162.

Reschke-Hernandez, A. E. (2011). History of music therapy treatment interventions for children with autism. Journal of Music Therapy, 48, 169-207, https://doi.org/10.1093/jmt/ 48.2.169.

Schwartzberg, E. T., \& Silverman, M. J. (2012). Effects of pitch, rhythm, and accompaniment on short- and long-term visual recall in children with autism spectrum disorders. The Arts in Psychotherapy, 39, 314-320, https://doi.org/10.1016/j.aip.2012.05.001.

Schwartzberg, E. T., \& Silverman, M. J. (2018). Effects of presentation style and musical elements on the sequential working memory of individuals with and without autism spectrum disorder. The Arts in Psychotherapy, 57, 43-49, https://doi.org/doi.org/10.1016/ j.aip.2017.10.002.

Sherer, M., Pierce, K., Paredes, S., Kisacky, K., Ingersoll, B., \& Schreibmen, L. (2001). Enhancing conversation skills in children with autism via video technology: Which is better, "self" or 'other" as a model? Behavioral Modifications, 25, 140-158, https://doi.org/ 10.1177/0145445501251008.

Shiner, B., Westgate, C. L., Harik, J. M., Watts, B. V., \& Schnurr, P. P. (2017). Effect of patienttherapist gender match on psychotherapy retention among United States veterans with posttraumatic stress disorder. Administration and Policy in Mental Health and Mental Health Services, 44, 642-650, https://doi.org/10.1007/s1048. 
Schwartzberg, E. T., \& Silverman, M. J. (2013). Effects of music-based social stories on comprehension and generalization of social skills in children with autism spectrum disorders: A randomized effectiveness study. The Arts in Psychotherapy, 40, 331-337, https://doi.org/10.1016/j.aip.2013.06.001.

Silverman, M. J., \& Schwartzberg, E. T. (2014a). Effects of voice timbre and accompaniment on working memory as measured by sequential monosyllabic digit recall performance. Journal of Music Therapy, 51, 171-185, https://doi.org/10.1093/jmt/thu009.

Silverman, M. J., \& Schwartzberg, E. T. (2014b). Effects of mode and rhythm on working memory as measured by sequential digit recall performance. Korean Journal of Music Therapy, 16, 93-105, https://doi.org/10.21330/kjmt.2014.16.1.93.

Simpson, K., \& Keen, D. (2011). Music interventions for children with autism: Narrative review of literature. Journal of Autism and Developmental Disorders, 41, 1507-1514, https://doi.org/10.1007/s10803-010-1172-y.

Thaut, M. H., Peterson, D. A., McIntosh, G. C., \& Hoemberg, V. (2014). Music mnemonics aid verbal memory and induce learning - related brain plasticity in multiple sclerosis. Frontiers in Human Neuroscience, 13, https://doi.org/10.3389/fnhum.2014.00395.

Verté, S., Geurts, H., Roeyers, H., Oosterlaan, J., \& Sergeant, J. (2006). Executive functioning in children with an autism spectrum disorder: Can we differentiate within the spectrum? Journal of Autism and Developmental Disorders, 36, 351-372, https://doi.org/10.1007/ s10803-006-0074-5.

Ward, G. (2002). Memory and Cognition (Vol. 30). A recency-based account of the list length effect in free recall, pp. 885-892, https://doi.org/10.3758/BF03195774.

Wang, B. T., Teng, C. W., \& Chen, H. T. (2015). Using ipad to facilitate English vocabulary learning. International Journal of Information and Education Technology, 5, 100-104.

Wintersteen, M. B., Mensinger, J. L., \& Diamond, G. S. (2005). Do gender and racial differences between patient and therapist affect therapeutic alliance and treatment retention in adolescents? Professional Psychology:Research and Practice, 36, 400-408, https://doi.org/10.1037/0735-7028.36.4.400. 